\title{
Some Problems of Sludge Management in The WasteWater Treatment Plants
}

\author{
Lidia Wolny
}
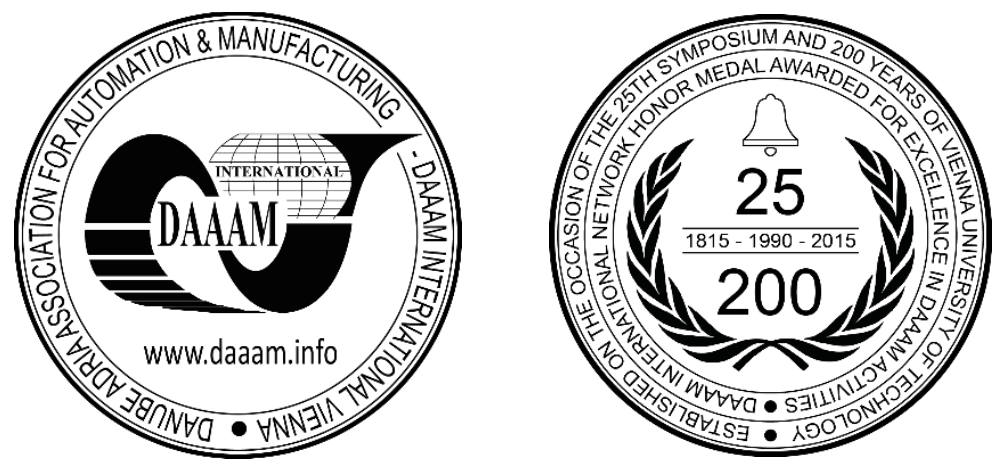

This Publication has to be referred as: Wolny, L[idia] (2018). Some Problems of Sludge Management in the Wastewater Treatment Plants, Proceedings of the 29th DAAAM International Symposium, pp.1197-1201, B. Katalinic (Ed.), Published by DAAAM International, ISBN 978-3-902734-20-4, ISSN 1726-9679, Vienna, Austria

DOI: $10.2507 / 29$ th.daaam.proceedings. 173

\begin{abstract}
Rational and safe (from the environmental point of view) sludge application is one of the important problems of sludge management. On the other hand, growing number of developed and exploited sewage treatment plants is the main reason for increasing amount of sludge arising. Development of new and effective technology of sewage treatment and more demanding requirements of sewage quality after treatment is also the reason for increasing amount of sludge that need utilization and management. The technologies of sludge dewatering in the scope of currently applied methods and devices were described. Because of increasing requirements to applied process and in the aspects of further management of sludge there is necessity of changes in this field. One of the most important processes of sludge management is dewatering. That is why in the theoretical part the significant factors influencing this process were presented. In the investigative part of this paper the methods of sludge dewatering in the selected wastewater treatment plants (WWTP) were analysed. The selected WWTP were chosen on the base of their through - put and mechanical method of sludge dewatering. The efficiency of centrifugation, belt pressing and bagging system was compared. In each case it was about $80 \%$.
\end{abstract}

Keywords: sewage sludge; hydration; dewatering; sludge management; efficiency

\section{Introduction}

Sewage sludge dewatering is one of the main operations applied in the processing of sewage sludge generated during wastewater treatment. This operation determines the volume of sewage sludge which is important for technical and economic aspects of the sewage sludge management. From the technical point of view the technology of sewage sludge dewatering should be selected based on the moisture content required for a given method of sewage sludge utilization. Also, this technology should be inexpensive and the most efficient in water removal [1], [2]. As a result of joining the European Union, the Polish legislation on the environmental protection and waste management has changed significantly. The National Wastewater Treatment Program has been approved and implemented by the Ministry of Environment in order to provide a transition necessary to adjust the Polish legislation to the European standards in wastewater management. 
Also, the construction of new sewage, rainwater and general draining systems and the development of new or existing wastewater treatment plants is planned in this Program. These goals will result in the reduced quantity of sewage sludge [3], [4], [5].

The paper presents the review of some technologies for sewage sludge dewatering applied in the selected local wastewater treatment plants. The impact of selected methods on the volume and sanitary characteristics of sewage sludge with reference to the possible methods of sewage sludge utilization was discussed.

\section{Sewage sludge - type, moisture content and utilization methods}

Due to the diversity of wastewater and the technologies applied to wastewater treatment, sewage sludge is a product (i.e. waste product) which shows different characteristics. Sewage sludge generated in the wastewater treatment processes can be classified according to the cycle of wastewater treatment and the applied separation processes.

The initial moisture content depends on the process stage in which sewage sludge was generated whereas the final content of dry matter depends on the applied dewatering processes (Table 1).

\begin{tabular}{|c|c|c|}
\hline Process & Initial moisture content, $\%$ & Final moisture content, $\%$ \\
\hline Thickening & 95 & 85 \\
\hline Dewatering & 85 & 60 \\
\hline Drying & 60 & $5-10$ \\
\hline
\end{tabular}

Table 1. Reduction in the moisture content of sewage sludge during dewatering [6]

Till now, landfilling was the most frequently applied method for the final utilization of sewage sludge. Therefore dewatering of sewage sludge was considered the most efficient method in terms of transportation and utilization at landfills. Joining the European Union imposed the significant changes in the final utilization procedures of sewage sludge in Poland. In consequence, Poland is obliged to manage municipal sewage sludge according to the legal standards currently in force in the European community.

With reference to the EU standards the treatment of municipal wastewater should be combined with a selected method for utilization of sewage sludge (the end product in a wastewater treatment process) in an environment friendly and economic manner [4], [7], [8]. However, different trends have been observed in other parts of the world. For example, in Australia the primary methods for sewage sludge utilization include production of biofuels (diesel oil) and a fertilizer in a form of dry granules [9].

\section{Characteristics of sewage sludge dewatering in the selected local wastewater treatment plants in Poland}

The wastewater treatment plants subjected to this analysis differ due to the applied technologies which are selected based on the characteristics of treated wastewater (Table 2).

\begin{tabular}{|cccc|}
\hline $\begin{array}{c}\text { Wastewater treatment } \\
\text { plant }\end{array}$ & $\begin{array}{c}\text { Design capacity } \\
\mathrm{m}^{3} / \mathrm{d}\end{array}$ & $\begin{array}{c}\text { Working capacity } \\
\mathrm{m}^{3} / \mathrm{d}\end{array}$ & $\begin{array}{c}\text { Population } \\
\text { equivalent }\end{array}$ \\
A & 9000 & 5140,33 & 50000 \\
B & 1650 & 686,28 & 9360 \\
C & 633 & 316,50 & 3590 \\
\hline
\end{tabular}

Table 2. The characteristics of the capacity for the selected local wastewater treatment plants

In the Wastewater Treatment Plant A the primary and thickened sewage sludge as well as fermented sewage sludge is transferred from the pumping system to the flocculation tank (Fig. 1) which is combined with the centrifuge. Sewage sludge is mixed with the flocculent F-82 (produced by a French manufacturer) and is subjected to centrifugation.

Sewage sludge is dewatered in the centrifuge (Fig. 2) and supernatant is collected in the designated tank and recycled through the settling tanks to the wastewater treatment process. Dewatered sewage sludge is fed to the conveyer belt and transferred outside of the centrifuge facility to sludge lagoons. 


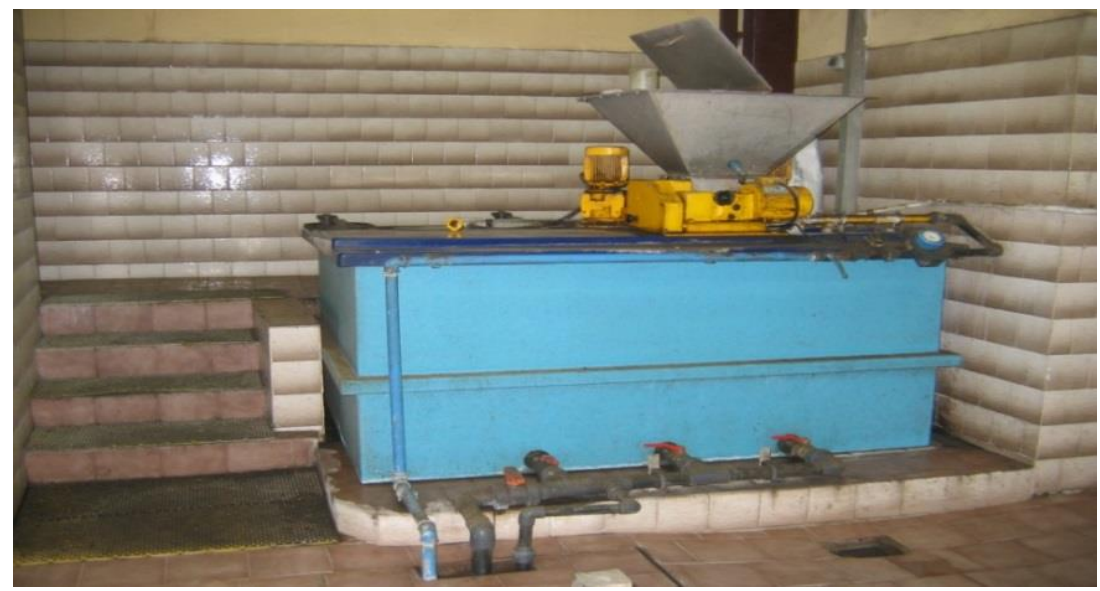

Fig. 1. The flocculation tank built-in the station of centrifuges in the wastewater treatment plant A

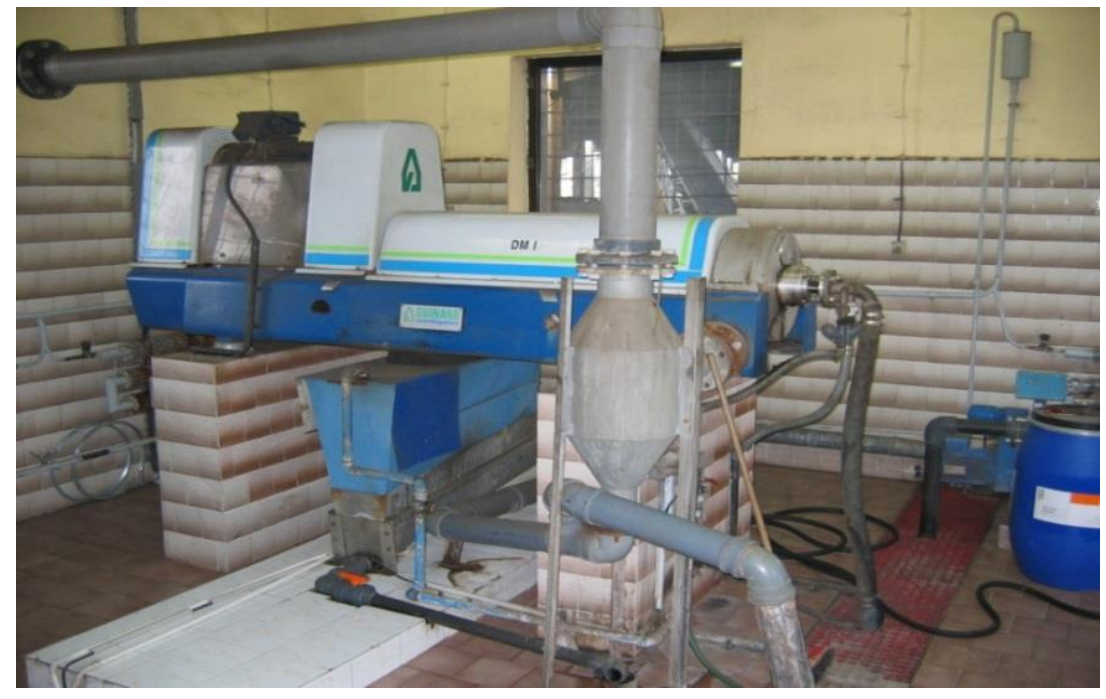

Fig. 2. The centrifuge in the section of centrifuges in the Wastewater Treatment Plant A

Processing of the primary sewage sludge in the Wastewater Treatment Plant B comprises the sewage sludge fermentation and thickening in the Imhoff tanks. Fermented and thickened sewage sludge is transferred gravitationally to the tank in the dewatering section, and then pumped into the belt filtration press (the DEWA system, N-PD 7L type) for dewatering (Fig. 3). The excessive sludge generated during the process of biological treatment is aerobically stabilized in the reactors. This is possible due to low content of contaminants and the age of sewage sludge.

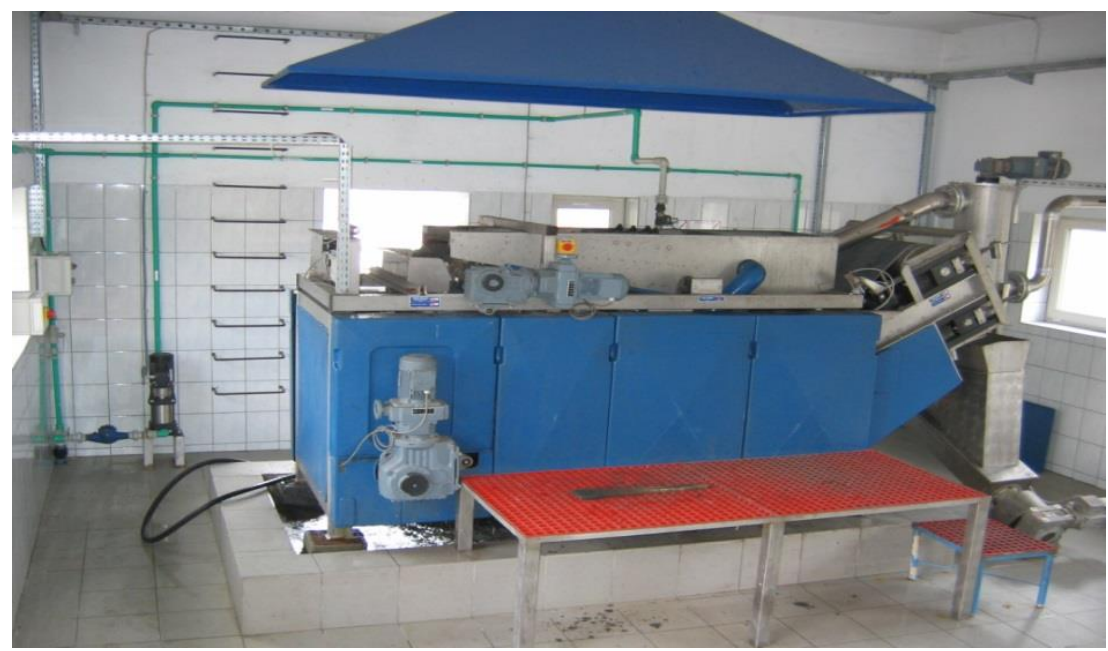

Fig. 3. The filtration belt press in the dewatering section in the Wastewater Treatment Plant B 
The primary sewage sludge in the Wastewater Treatment Plant $\mathrm{C}$ is subjected to aerobic stabilization in the sludge tank. Fermented and thickened sewage sludge is transferred gravitationally to the tank, and then pumped into the sackfilling machine (DRAIMAD 6) for dewatering (Fig. 4). The excessive sludge above $300 \mathrm{ml} / \mathrm{l}$ generated during biological treatment is aerobically stabilized in the tank.

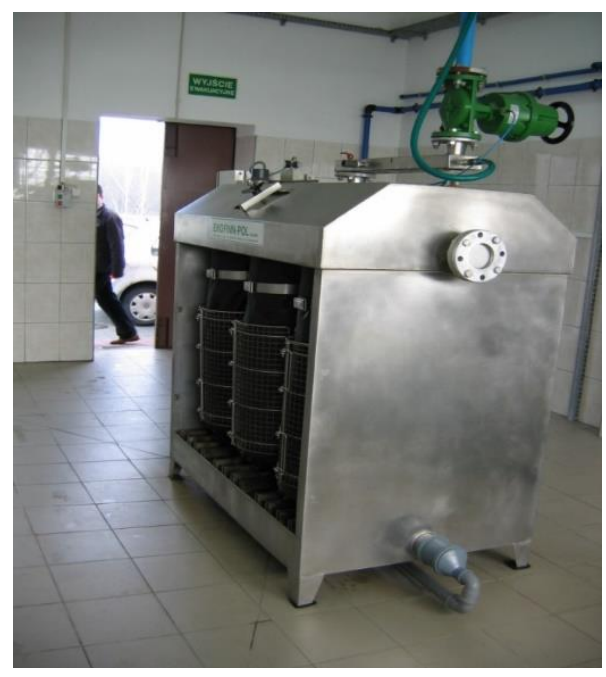

Fig. 4. The sack-filling machine in the dewatering section in the Wastewater Treatment Plant C

In order to analyze the process of dewatering in the selected wastewater treatment plants the equipment used in the process was compared with the type and quantity of generated sludge (Table 3).

\begin{tabular}{|c|c|c|c|}
\hline Water treatment plant & Equipment & Type of sludge & $\begin{array}{c}\text { Quantity of sludge } \\
\mathrm{Mg}\end{array}$ \\
\hline A & centrifuge & $\begin{array}{c}\text { fermented sewage } \\
\text { sludge }\end{array}$ & 3377 \\
\hline B & belt press & stabilized sewage sludge & 639 \\
\hline C & sack-filling machine & stabilized sewage sludge & 40 \\
\hline
\end{tabular}

Table 3. The comparison of the quantity of sludge and the type of equipment

The conducted investigations show that the methods and equipment applied for sewage sludge dewatering in the sewage sludge section in the selected wastewater treatment plants are efficient. With reference to the quantity of generated sewage sludge (Table 3) the methods for sewage sludge utilization are suitable for the utilization of the presented quantities of sewage sludge after dewatering. The analysis of sewage sludge management in the presented wastewater treatment plants shows that the applied methods result in sufficient reduction in the water content, and thus the volume of sludge (Table 4).

\begin{tabular}{|c|c|c|c|}
\hline Wastewater treatment plant & Equipment & Initial water content & Final water content \\
\hline A & centrifuge & $95 \%$ & $80-75 \%$ \\
\hline B & belt press & $96 \%$ & $78 \%$ \\
\hline C & sack-filling machine & $98 \%$ & $80 \%(40 \%)^{*}$ \\
\hline
\end{tabular}

()$^{*}$ after seasoning

Table 4. The reduction in the water content of sewage sludge in the analyzed wastewater treatment plants

\section{The analysis of the final utilization of sewage sludge}

Sewage sludge from the Wastewater Treatment Plan A shows a high moisture content, slight acidity and a very high content of cadmium. In consequence, this sludge can be used neither for agricultural purposes nor industrial landfill reclamation. What is more, it is contaminated with microorganisms but does not contain any parasites. 
This sludge is deposited at the post-mining excavation. As for the sewage sludge from the Wastewater Treatment Plant B, it shows slight acidity and the content of heavy metals does not exceed the permissible values, and thus can be used for land purposes by hydroseeding. With reference to the currently valid legislation, no analyses were conduced for methods of sewage sludge utilization or management other than landfilling. Also, no investigations were conducted in order to determine the usability of sewage sludge from the Wastewater Treatment Plant $\mathrm{C}$ as a substrate for agricultural purposes or a secondary substrate for further processing. At present, this sewage sludge is deposited at a landfill. The Water Supply and Sewerage Company from the municipality A which uses the wastewater treatment plants in the municipality A and B is investigating the possibility of the utilization of sewage sludge for agricultural purposes. Prior to the agricultural utilization, sewage sludge should be subjected to composting. This is feasible as the Wastewater Treatment Plant A poses sludge lagoons which after modernization can be used for composting. Also, thermal method for sewage sludge utilization was investigated.

Landfilling which is currently applied method for sewage sludge utilization should be replaced in near future by other methods due to the implementation of new legal regulations and increasing quantities of sewage sludge which is caused by expanding the sewage sludge system (accordingly to the National Program for Municipal Wastewater Treatment valid till 2015) [3].

\section{Conclusion}

As a consequence of the adjustments introduced to the Polish law by implementing the EU requirements and the relevant Directives, the management of sewage sludge has to be changed. Biodegradable municipal sewage sludge can not be deposited at landfills but has to be used for land reclamation. This generally applies to small local wastewater treatment plants. Therefore, the sewage sludge management and the selection of equipment and operations should be focused on utilization of sewage sludge as a substrate not a waste product. The important aspect in this process is the hygienization of sewage sludge with simultaneous dewatering with the result relevant to the selected utilization method for the generated substrate.

Despite the technological adjustments and processes, the essential aspect in changing the present state of the sewage sludge management is establishing a mutual agreement between the parties responsible for the protection and management of natural environment. The local governments and the institutions for the protection of environment have to undertake the actions to increase the awareness of the society in order to get the approval for the utilization of sewage sludge by land reclamation. This is of great importance as the social awareness of the environment protection and construction of facilities for sewage sludge processing is increasing.

In case of large wastewater treatment plants which 'produce' sewage sludge of more diversified contents and quality, the utilization of sewage sludge can pose many difficulties. The utilization of sewage sludge, and thus the process of dewatering, should be directed towards the energy recovery by thermal methods. The construction of incineration plants or further processing of sewage sludge into fuel materials is often too expensive for the mangers at wastewater treatment plants. These methods should be applied by the local governments, often with the support of the province authorities in the frame of the regional and provincial strategies for waste management. The incineration plants or processing facilities can be profitable if more contractors use their services.

\section{Acknowledgments}

The research was funded by BS/PB-401-301/11 resources.

\section{References}

[1] Oleszkiewicz, J. (1998). Sewage sludge management-vademecum of decision-maker. Wydawnictwo LEM, Kraków (in Polish).

[2] Muller, J. (2000). Sewage sludge disintegration as key - step in sewage sludge minimization. Wat. Sci. Technol., Vol. 41, No. 8, pp. 123-130.

[3] National Wastewater Treatment Program. (2004). IMiGW, Warsaw (in Polish)

[4] Kremljak, Z. (2017). Economy of Biogas Plants, Proceedings of the 28th DAAAM International Symposium, pp. 0136-0143, B. Katalinic (Ed.), Published by DAAAM International, ISBN 978-3-902734-11-2, ISSN 1726-9679, Vienna, Austria

[5] Spinosa, L. (2001). Evolution of sewage sludge regulations in Europe. Wat. Sci. Technol., Vol. 44, No 10, pp. 1-8.

[6] Bień, J.B. (2007). Sewage sludge - theory and practice. Czestochowa University of Technology, Czestochowa (in Polish)

[7] Kuglarz, M.; Wolny, L. \& Korzekwa-Wojtal, A. (2008). Sludge management in the selected small wastewater treatment plants. Environmental Engineering, the 7th International Conference, Lithuania.

[8] Spinosa, L. \& Leschber, R. (2008). Developments in sludge characterization in Europe. ECSM'08 - European Conference on Sludge Management, Belgium.

[9] Siarkiewicz, A. (2000). Water and sewage management in Perth (Western Australia). Gaz, Woda i Technika Sanitarna, 8/2000, 337 (in Polish) 